\title{
Plant breeding to control zinc deficiency in India: how cost-effective is biofortification?
}

\author{
Alexander J Stein ${ }^{1, *}$,Penelope Nestel ${ }^{2}$, JV Meenakshi ${ }^{2}$, Matin Qaim ${ }^{1}$, HPS Sachdev ${ }^{3}$ and \\ Zulfiqar A Bhutta ${ }^{4}$ \\ 'Division of International Agricultural Trade and Food Security, University of Hohenheim (490b), 70593 Stuttgart, \\ Germany: ${ }^{2}$ HarvestPlus, International Food Policy Research Institute, Washington, DC, USA: ${ }^{3}$ Sitaram Bhartia \\ Institute of Science and Research, New Delhi, India: ${ }^{4}$ Department of Paediatrics and Child Health, Aga Khan \\ University, Karachi, Pakistan
}

Submitted 5 December 2005: Accepted 25 April 2006

\begin{abstract}
Objective: To estimate the potential impact of zinc biofortification of rice and wheat on public health in India and to evaluate its cost-effectiveness compared with alternative interventions and international standards.

Design: The burden of zinc deficiency $(\mathrm{ZnD})$ in India was expressed in disabilityadjusted life years (DALYs) lost. Current zinc intakes were derived from a nationally representative household food consumption survey (30-day recall) and attributed to household members based on adult equivalent weights. Using a dose-response function, projected increased zinc intakes from biofortified rice and wheat were translated into potential health improvements for pessimistic and optimistic scenarios. After estimating the costs of developing and disseminating the new varieties, the costeffectiveness of zinc biofortification was calculated for both scenarios and compared with alternative micronutrient interventions and international reference standards. Setting: India.

Subjects: Representative household survey $(n=119554)$.

Results: The calculated annual burden of $\mathrm{ZnD}$ in India is 2.8 million DALYs lost. Zinc biofortification of rice and wheat may reduce this burden by $20-51 \%$ and save $0.6-$ 1.4 million DALYs each year, depending on the scenario. The cost for saving one DALY amounts to \$US $0.73-7.31$, which is very cost-effective by standards of the World Bank and the World Health Organization, and is lower than that of most other micronutrient interventions.

Conclusions: Not only may zinc biofortification save lives and prevent morbidity among millions of people, it may also help accommodate the need to economise and to allocate resources more efficiently. Further research is needed to corroborate these findings.
\end{abstract}

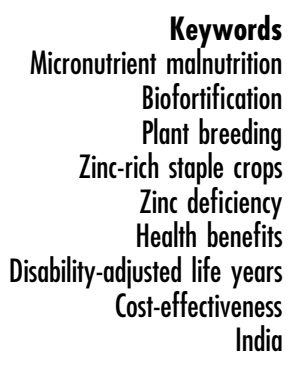

Adequate intake of nutritious foods is a prerequisite to achieving and maintaining good health and well-being. Millions of people worldwide, however, are unable to achieve this. An estimated 852 million people do not eat sufficient food to meet their energy requirements and are consequently undernourished. Many more people suffer from 'hidden hunger': 150 million are vitamin-A-deficient, almost 2 billion are iodine-deficient, between 4 and 5 billion are iron-deficient ${ }^{1}$ and about 2.7 billion are zincdeficient $^{2}$. This imbalance between 'overt' and 'hidden' hunger is underlined in the report of the United Nations Millennium Project's Task Force on Hunger $^{3}$, where the authors call for further investments in agriculture and confirm the major role that agricultural research has played in reducing hunger. Indeed, the advent of the Green Revolution in the 1960s - in which high-yielding crop varieties were introduced and combined with more intense use of inputs, such as irrigation and agrochemicals - was instrumental in increasing the food supply in developing countries. The general concern today is less about whether there is sufficient food in the world, but rather how to distribute and ensure access for those in need without compromising their independence, selfreliance and dignity. $\dagger$

Historically, the control of micronutrient malnutrition has been under the domain of public health, rather than agriculture, despite the same underlying cause: an

this is not to say that the Green Revolution did not have its shortcomings and weaknesses. By solving some problems new ones were created - not least a shift in the consumption patterns of the poor towards cheap but monotonous cereal-based diets ${ }^{4}$. 
inadequate intake of a balanced diet. This was because clinical deficiencies were widespread and control was driven by the medical model that focused on the provision of therapeutic and preventive pharmaceutical supplements, such as iron or iron-folate tablets to pregnant women or of vitamin A capsules to older infants and young children. More recently food fortification has come to the fore: for example, salt iodisation; flour fortification with iron; and fortification of sugar and cooking oil with vitamin A.

Pharmaceutical supplementation and food fortification gained acceptance as viable options once it was deemed they were very cost-effective $e^{2,5-7}$. Yet, as with all interventions, impact depends on coverage. The further the programme is from urban centres and the more it targets people at the margin of society, the more difficult and expensive it is to increase coverage ${ }^{2}$. Rural people, and to a certain extent the urban poor, tend to eat less processed food; thus they are often not reached by food fortification programmes, especially where both the food industry and food market infrastructure are immature. Likewise, a weak health infrastructure coupled with discrimination can limit the effectiveness and efficiency of pharmaceutical supplementation programmes. Moreover, both fortification and supplementation programmes require financial commitment year on year, either directly by the government or donors, or indirectly through voluntary measures (e.g. donated labour/ time or absorbing the marginal cost of fortification) or higher prices for fortified foodstuffs. Monitoring the fortificant levels in food or the coverage of either programme imposes additional administrative burdens.

Because micronutrient malnutrition is the consequence of a lack of access to adequate quality food and the existing interventions are not easy to implement in all areas, a new initiative was started recently in which food quality is recognised as an important agricultural objective. The means to fulfil this objective includes breeding crops - notably staple foods - both for higher yields and higher micronutrient content, an approach known as biofortification $^{8,9}$. This approach has multiple advantages, including the fact that it capitalises on the regular daily intake of a consistent amount of food staple by all family members, and, because staple foods predominate in the diets of the poor, this strategy implicitly targets low-income households ${ }^{10}$. Biofortification also provides a feasible means of reaching micronutrient-deficient populations in relatively remote rural areas. (For example, subsequent to the introduction of modern wheat varieties to India in the mid1960 s, adoption rates exceeded $70 \%$ within 10 years ${ }^{11}$.) Thus biofortification can deliver naturally fortified foods to people with limited access to commercially marketed fortified foods that are more readily available in urban areas ${ }^{10}$. Because farmers will not adopt new crops unless they provide an agronomic and/or economic advantage, the strategy is to introduce high zinc content as a standard trait for releases of new varieties (that have desirable agronomic properties) or to introduce the zinc-rich trait into new releases of popular varieties. As such, there will be only marginal costs for distribution and marketing.

Zinc deficiency ( $\mathrm{ZnD}$ ) is one of the five leading risk factors that contribute to the burden of disease in developing countries with high mortality rates ${ }^{2}$. Despite this, the extent and severity of $\mathrm{ZnD}$ have not received the attention given to others, notably iodine, iron and vitamin $\mathrm{A}^{12,13}$, largely because of the difficulty in measuring zinc status. With a better understanding of the consequences of $\mathrm{ZnD}$ and the development of proxy indicators for deficiency, concerted efforts are now being made to control $\mathrm{ZnD}$. One of these is to breed crops for higher zinc content, a goal of the HarvestPlus programme.*

To provide a common framework for estimating the effectiveness $t$ and cost-effectiveness of zinc biofortification, and to compare biofortification with conventional fortification and pharmaceutical supplementation programmes, Stein et al. ${ }^{14}$ developed a model based on disability-adjusted life years (DALYs). This model can be used to measure both the current burden of $\mathrm{ZnD}$ and the likely impact of biofortification, and it also enables economic analyses of the related costs and benefits. The present paper reports the outcome of the first application of this framework, to the introduction of zinc-rich wheat and zinc-rich rice in India to control $\mathrm{ZnD}$. Because the specific varieties are still at the stage of research and development (R\&D), the analysis is necessarily carried out as an ex-ante study.

The International Zinc Nutrition Consultative Group ${ }^{12}$ estimates that $26 \%$ of the Indian population is at risk of inadequate zinc intakes. Clearly $\mathrm{ZnD}$ in India is a public health problem that warrants a detailed analysis, and the present paper starts with this. It then goes on to show the potential impact of zinc biofortification on the burden of $\mathrm{ZnD}$ in India. The focus is on wheat and rice given that India is divided into predominantly wheat-eating and riceeating states (Fig. $1^{15}$ ).

A 'recommended action' of the World Health Report ${ }^{2}$ is that 'cost-effectiveness analyses should be used to identify high, medium and low priority interventions to prevent or reduce risks, with highest priority given to those interventions that are cost-effective and affordable' (p. 11). Therefore, in the third and final step, the cost-effectiveness of zinc biofortification is analysed. The latter is significant because biofortification is proposed as a complementary intervention to conventional fortification and preventive pharmaceutical supplementation; thus it is important to know whether biofortification uses scarce resources as efficiently as the existing interventions.

*HarvestPlus is the biofortification programme of the Consultative Group on International Agricultural Research that was started in 2004. The programme focuses on iron, zinc and $\beta$-carotene.

†Here, effectiveness is based on the efficaciousness of zinc interventions coupled with projected coverage. 


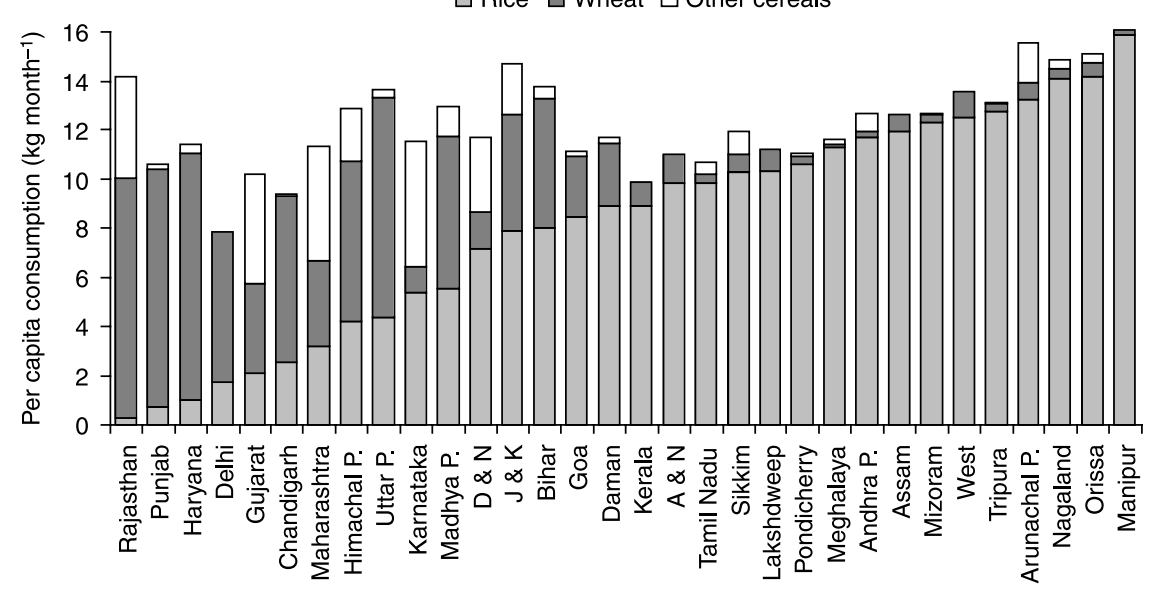

Fig. 1 Average per capita consumption of cereals $\left(\mathrm{kg} \mathrm{month}^{-1}\right)$ in rural India, per state, 1999/2000 ${ }^{15}$ (P. - Pradesh; D \& N - Dadra and Nagar; J \& K - Jammu and Kashmir)

\section{Methods}

The burden of $\mathrm{ZnD}$ in India was quantified using the DALY method, in which morbidity is assigned a weight and combined with information on mortality to give a common measure of ill health ${ }^{14,16,17}$. Four per cent of all under-fives mortality can be prevented if all children have sufficient intakes of absorbable zinc ${ }^{18}$. The known adverse health outcomes from $\mathrm{ZnD}$ that do not necessarily result in death are diarrhoea $^{19,20}$, pneumonia ${ }^{21}$ and stunting ${ }^{22}$. The target groups for these conditions included both infants (below 1 year of age) and children (1-5 years of age). The incidence rates, disability weights and durations used for each condition are shown in Table $1^{14,23,24}$. To derive the remaining life expectancy in the case of child mortality and for duration of stunting, which was considered a permanent condition, standard life tables for India were used ${ }^{25}$. The size of the target groups were taken from Census of India data ${ }^{26,27}$.

The 55th survey of the Indian National Sample Survey Organisation $^{15}$ - which is a representative survey that included 120000 households - was used to compute zinc intakes. Household-level data on the quantities and volumes of the foodstuffs and beverages consumed in the preceding month were multiplied by their respective zinc content using Indian food composition tables ${ }^{28}$ * For the few foods for which national composition values were not available, the corresponding zinc values in the US food

*The survey not only recorded food expenditure but also the amounts of over 140 different foodstuffs consumed by the household over a 30 -day recall period. According to the survey $\operatorname{codebook}^{15}$, the instructions for the interviewers were to include all consumption of monetary and non-monetary purchases and goods received, as well as all household consumption from livestock keeping (like milk, meat or eggs) and consumption from transfer receipts. Hence, household consumption comprises (1) commodities purchased in cash, (2) commodities received in exchange of goods and services, (3) homegrown/home-produced stock, (4) transfer receipts such as gifts, loans, charities, etc. and (5) free collection. composition table were used ${ }^{29}$; given the small number of less important food items concerned, a potential bias because of underlying differences in the zinc content of the soil is expected to be insignificant. The survey data for household composition and the energy requirements of Indians ${ }^{28}$ in different age and gender groups were used to compute the zinc intake per adult equivalent in each household (i.e. the assumption is that there is no general, nationwide and persistent bias in the distribution of food within the households ${ }^{30,31}$ ). The estimated zinc intake of individual household members was then calculated as a proportion of the adult equivalent.

Future consumption of biofortified wheat and rice will lead to higher zinc intakes and reduce the incidence of deficiency-related health conditions. To anticipate changes in zinc intakes, the food composition values of zinc for wheat and rice were replaced with the assumed increases in zinc contents through biofortification; the latter were used to derive projected zinc intakes. As neither biofortified wheat nor biofortified rice has been released, the projected increases in zinc contents were estimated by the plant breeders at the International Rice Research Institute and the International Maize and Wheat Improvement Centre based on the variation in zinc concentrations found in the germplasm screening. The plant breeders and other experts also estimated potential coverage rates for both crops 20 years after release (Fig. 2). Because of the multiple sources of uncertainty arising from these estimations, an optimistic-pessimistic scenario approach was chosen (Table 2) to increase the reliability of the results ${ }^{32}$; for the potential coverage rate, a further sensitivity analysis was carried out to determine the lowest bound at which zinc biofortification can still be considered cost-effective.

Current zinc intakes together with the potential zinc intakes from biofortified wheat and rice (which were simulated based on the food consumption data, the food composition information and the expected zinc content in wheat and rice; Table 2) and the estimated average 
Table 1 Data used to calculate disability-adjusted life years lost due to ZnD in India

\begin{tabular}{|c|c|c|c|c|c|}
\hline Health outcome related to $\mathrm{ZnD}$ & Target group & $\begin{array}{l}\text { Incidence } \\
\text { rate }^{*}\end{array}$ & $\begin{array}{l}\text { Disability } \\
\text { weight } †\end{array}$ & $\begin{array}{l}\text { Duration } \\
\text { of disease }\end{array}$ & $\begin{array}{l}\text { Age of death/ } \\
\text { onset of disease }\end{array}$ \\
\hline \multirow[t]{2}{*}{ Diarrhoea } & Infants & 0.468 & 0.2 & 3 days & $\mathrm{N} / \mathrm{A}$ \\
\hline & Children & 0.234 & 0.15 & 4 days & N/A \\
\hline \multirow[t]{2}{*}{ Pneumonia } & Infants & 0.119 & 0.3 & 4 days & N/A \\
\hline & Children & 0.119 & 0.2 & 4 days & $\mathrm{N} / \mathrm{A}$ \\
\hline Stunting & Infants & $0.455 \ddagger$ & 0.0001 & Rest of life & 6 months \\
\hline \multirow[t]{2}{*}{ Mortality } & Infants & $0.0027 \S$ & N/A & N/A & 8 months \\
\hline & Children & $0.001 \S$ & $\mathrm{N} / \mathrm{A}$ & $\mathrm{N} / \mathrm{A}$ & 2 years \\
\hline
\end{tabular}

ZnD - zinc deficiency; N/A - not applicable.

* Fraction of target group that experiences the health outcome.

† Extent of disability that is caused by the health outcome (perfect health corresponds to a weight of 0 , death to a weight of 1 )

Source: reference 14, ¥reference 23, §reference 24.

requirements for zinc for individuals consuming unrefined, cereal-based diets ${ }^{12}$ were used to calculate separate efficacy ratios at the individual level for both scenarios. These efficacy ratios are based on the notion that a given absolute increase in zinc intake will have a bigger impact on the health of a very deficient individual than on the health of an almost sufficient individual: the more deficient a person is, the higher the efficacy of a given increment in zinc intake ${ }^{14}$. To calculate new incidence and mortality rates, mean efficacy ratios were derived for the target groups. These new rates were used to recalculate the burden of $\mathrm{ZnD}$ in India with biofortification for the two scenarios. The difference to the number of DALYs lost in the status quo is the impact of biofortification.

Finally, the number of DALYs that could be saved through biofortification was juxtaposed on the costs of biofortifying wheat and rice to determine the costeffectiveness of the intervention. The costs for the optimistic scenario were derived from the HarvestPlus budget $^{33}$ as the development of the new varieties is being funded through this programme; for the pessimistic scenarios these figures were doubled, making this a conservative assumption. The expected time required for R\&D was estimated by the lead plant breeders ( $G$ Barry and I Ortiz-Monasterio, personal communication, December 2004) (Table 3). The time horizon of the analyses was set at 30 years, which is a common time frame for economic analyses because after that time discounting levels the impact of future events. In the present context, it also covers the life cycle of the biofortified crops from the initial R\&D until the maximum assumed coverage of these crops (Fig. 2). To discount future costs and benefits to the base year, a $3 \%$ rate was used ${ }^{14}$. R\&D costs were attributed to the main target countries according to their respective production shares.* Potentially, other countries can also

*For wheat the main target countries are India and Pakistan; for rice the main target countries are India, Bangladesh and the Philippines. In the optimistic scenario the costs were moreover shared amongst secondary target countries (China, Indonesia and Vietnam for rice, and China for wheat). benefit from biofortified wheat or rice, but costs tend to be underestimated ex-ante. This warrants a cautious approach when projecting costs into the future. Also, the actual adoption of biofortified varieties is still an open issue.

\section{Results}

The current burden of $\mathrm{ZnD}$ in India amounts to 2.8 million DALYs lost, 2.7 million from mortality and 140000 from morbidity, $70 \%$ of which occurs among infants (Fig. 3). With zinc biofortification of wheat and rice 0.6 million DALYs can be saved each year in the pessimistic scenario, while 1.4 million DALYs can be gained annually under the optimistic assumptions. This corresponds to a reduction of the burden of $\mathrm{ZnD}$ of 20 and 51\%, respectively (Table 4). Yet, while the biggest burden of $\mathrm{ZnD}$ is borne by infants, the biggest health gain through biofortification occurs among children aged 15 years (Fig. 4). If these health benefits are set against the costs to be incurred for zinc biofortification of wheat and rice for India, and if all values are discounted to the base year, saving one healthy life year through biofortification costs \$US 7.31 under the pessimistic assumptions or as little as \$US 0.73 in the optimistic scenario.

Expressed in mortality figures only, the annual burden of $\mathrm{ZnD}$ in India is 95500 deaths; with zinc biofortification 18350 and 48100 lives can be saved in the pessimistic and optimistic scenario, respectively. Juxtaposing the net present cost and the (undiscounted) number of infant and child deaths that can be averted within the 30-year time frame yields a cost of \$US 115 per life saved in the pessimistic scenario, while under optimistic assumptions saving one life through zinc biofortification costs only \$US 12 (Table 5).

\section{Discussion}

The results show that $\mathrm{ZnD}$ imposes a heavy burden on public health in India, most of it due to mortality associated with impaired immune function and thus greater susceptibility to infectious diseases. With 2.8 million DALYs lost each year, the burden is lower than the burden of 4 million DALYs lost in India due to 


\begin{tabular}{|c|c|c|c|c|c|c|c|c|c|c|c|c|c|c|c|c|c|c|c|c|c|c|c|c|c|c|c|c|c|c|c|}
\hline Year & & 1 & 2 & 3 & 4 & 5 & 6 & 7 & 8 & 9 & 10 & 11 & 12 & 13 & 14 & 15 & 16 & 17 & 18 & 19 & 20 & & 22 & 23 & 24 & 25 & & 627 & 28 & 29 & 30 \\
\hline \multirow{2}{*}{$\begin{array}{l}\text { Pessimistic } \\
\text { scenario }\end{array}$} & Activities & \multicolumn{9}{|c|}{ Basic R\&D } & \multicolumn{7}{|c|}{ Country-specific activities ${ }^{*}$} & \multicolumn{13}{|c|}{ Maintenance breeding } & \\
\hline & Coverage(\%) & 0 & 0 & 0 & 0 & 0 & 0 & 0 & 0 & 0 & $\ldots$ & 3 & & 6 & $\ldots$ & 9 & $\ldots$ & 12 & $\ldots$ & 15 & & 18 & $\ldots$ & 21 & & 24 & - & 27 & & 30 & 30 \\
\hline \multirow{2}{*}{$\begin{array}{l}\text { Optimistic } \\
\text { scenario }\end{array}$} & Activities & \multicolumn{7}{|c|}{ Basic R\&D } & \multicolumn{5}{|c|}{ Country-specific act. ${ }^{*}$} & \multicolumn{17}{|c|}{ Maintenance breeding } & \\
\hline & Coverage(\%) & 0 & 0 & 0 & 0 & 0 & 0 & 0 & $\ldots$ & 5 & $\ldots$ & 10 & .. & 15 & $\ldots$ & 20 & $\ldots$ & 25 & $\ldots$ & 30 & $\ldots$ & 35 & $\ldots$ & 40 & & 45 &.. & 50 & 50 & 50 & 50 \\
\hline
\end{tabular}

Fig. 2 The time frame and adoption rates for the analysis of zinc biofortification (for the example of zinc-rich wheat). *The assumption is that some of the advanced lines released by the International Rice Research Institute and the International Maize and Wheat Improvement Centre are suitable for immediate cultivation in India. Additional biofortified varieties are then released in the course of the country-specific activities. It is also assumed that the varieties with the biggest potential coverage are adapted first. Also see Tables 2 and 3 (R\&D - research and development; act. - activities) 
Table 2 Assumptions about the success of zinc biofortification of wheat and rice

\begin{tabular}{|c|c|c|c|c|}
\hline & \multicolumn{2}{|c|}{ Wheat $^{*}$} & \multicolumn{2}{|c|}{ Ricet } \\
\hline & Pessimistic scenario & Optimistic scenario & Pessimistic scenario & Optimistic scenario \\
\hline Current zinc content (ppm) & \multicolumn{2}{|c|}{31 for whole-wheat flour } & \multicolumn{2}{|c|}{13 for milled rice } \\
\hline Potential zinc content (ppm) & 37 & 55 & 24 & 35 \\
\hline Potential increase (\%) & 20 & 77 & 85 & 169 \\
\hline Potential coverage rate (\%) & 30 & 50 & 20 & 50 \\
\hline
\end{tabular}

PPM - parts per million.

Source: *I Ortiz-Monasterio and †G Barry (personal communication, 2006).

Table 3 Assumptions about costs of zinc biofortification of wheat and rice

\begin{tabular}{|c|c|c|c|c|}
\hline & \multicolumn{2}{|c|}{ Wheat } & \multicolumn{2}{|c|}{ Rice } \\
\hline & $\begin{array}{c}\text { Pessimistic } \\
\text { scenario }\end{array}$ & $\begin{array}{l}\text { Optimistic } \\
\text { scenario }\end{array}$ & $\begin{array}{l}\text { Pessimistic } \\
\text { scenario }\end{array}$ & $\begin{array}{l}\text { Optimistic } \\
\text { scenario }\end{array}$ \\
\hline \multicolumn{5}{|l|}{ Average annual costs (\$US million) } \\
\hline Basic R\&D (screening, breeding, testing, release of advanced line) & 1.4 & 0.7 & 1.6 & 0.8 \\
\hline Country-specific activities (adaptive breeding, dissemination, extension) & 0.8 & 0.5 & 0.8 & 0.5 \\
\hline Maintenance breeding & 0.2 & 0.1 & 0.2 & 0.1 \\
\hline \multicolumn{5}{|l|}{ Duration (years) } \\
\hline Basic R\&D & 9 & 7 & 8 & 6 \\
\hline Country-specific activities & 7 & 5 & 5 & 3 \\
\hline Maintenance breeding & \multicolumn{4}{|c|}{ Until end of 30 -years period } \\
\hline
\end{tabular}

R\&D - research and development.

Source: Based on reference 32, I Ortiz-Monasterio and G Barry (personal communication, 2004).

iron-deficiency anaemia ${ }^{34}$, but it still poses a problem of a considerable magnitude.* $\mathrm{ZnD}$ has received little public attention, and no systematic interventions are currently in place to control this micronutrient deficiency ${ }^{35}$. This analysis shows that zinc biofortification of wheat and rice in India may be an effective means to reduce the burden of ZnD. Given the higher natural zinc content in existing wheat varieties and the lower potential increases in biofortified wheat compared with rice, the impact of wheat biofortification is lower than the impact of rice biofortification. Nevertheless, by biofortifying not only rice but also wheat, it may be possible to reduce the burden of $\mathrm{ZnD}$ by an additional $2-10 \%$, i.e. by $60000-$ 290000 DALYs. $\dagger$ The impact of zinc biofortification is not completely additive, because if both crops are biofortified some consumers might already achieve sufficiency with the consumption of one crop only and hence biofortification of the other crop does not bring any additional benefit to these individuals.

A limitation of this analysis is the use of household-level rather than individual-level food intake data, because nationally representative food intake data are not currently

"While the burden of mortality is bigger for $\mathrm{ZnD}$ than for irondeficiency anaemia (IDA), the burden of morbidity is bigger for IDA than for $\mathrm{ZnD}$ simply because many more people are affected by IDA. (Because DALYs capture both mortality and morbidity they are a more appropriate measure of ill health than mortality rates.)

${ }^{\dagger}$ Another, future possibility could be to biofortify rice and wheat not only with zinc but also with iron to address multiple micronutrient deficiencies simultaneously. (a)

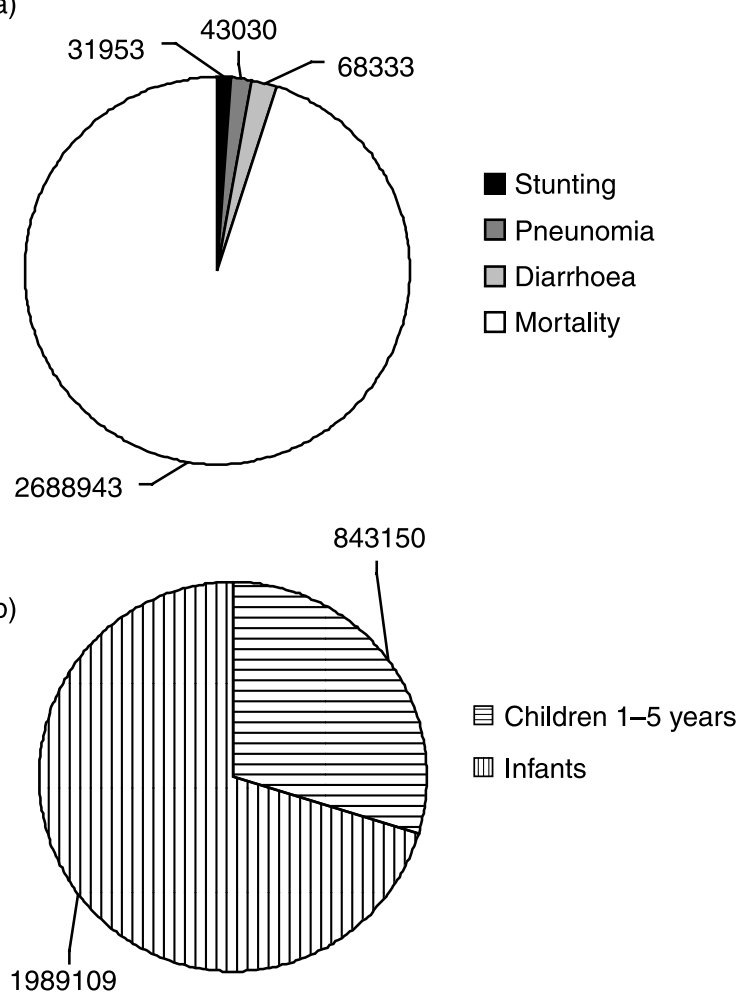

Fig. 3 Number of disability-adjusted life years (DALYs) lost due to the different health outcomes of zinc deficiency (a) and number of DALYs lost by the two target groups (b) 
Table 4 Potential impact of zinc biofortification on the burden of $\mathrm{ZnD}$ in India

\begin{tabular}{|c|c|c|c|c|}
\hline Crop & Scenario & DALYs lost due to $\mathrm{ZnD}$ & $\begin{array}{l}\text { DALYs gained relative } \\
\text { to status quo }\end{array}$ & $\begin{array}{l}\text { Reduction of burden } \\
\text { of } \mathrm{ZnD}(\%)\end{array}$ \\
\hline \multicolumn{2}{|c|}{ Status quo } & 2830000 & N/A & $\mathrm{N} / \mathrm{A}$ \\
\hline \multirow[t]{2}{*}{ Wheat } & Pessimistic & 2770000 & 60000 & 2 \\
\hline & Optimistic & 2510000 & 330000 & 12 \\
\hline \multirow[t]{2}{*}{ Rice } & Pessimistic & 2330000 & 500000 & 18 \\
\hline & Optimistic & 1670000 & 1160000 & 41 \\
\hline \multirow[t]{2}{*}{ Wheat and rice } & Pessimistic & 2270000 & 560000 & 20 \\
\hline & Optimistic & 1390000 & 1450000 & 51 \\
\hline
\end{tabular}

ZnD - zinc deficiency; DALY - disability-adjusted life year; N/A - not applicable.

available. Consequently, the use of adult equivalent weights to attribute a share of the household's overall consumption to each household member only approximates actual individual intakes, and may significantly overestimate infant intakes. However, if maternal zinc status can be improved through (long-term) consumption of zinc-biofortified rice and wheat, it is plausible that the status of her newborn infant will be better than it otherwise would be; consequently, infants may be less at-risk of succumbing to morbidity due to infectious diseases. Our approach is already a notable improvement over previous work (for vitamin A deficiency) that used highly aggregated national average consumption data as the basis for projecting the potential impact of a biofortified $\operatorname{crop}^{17}$. It is also an improvement over the use of national food balance data to assess population zinc status ${ }^{36}$, which are production-based and reflect average nutrient availability at the national level only - i.e. the use of household data and adult equivalent weights allows for estimating intakes at a more disaggregated level. Clearly further research with better data is necessary to corroborate the findings. None the less, the approach used here provides important preliminary findings for policy-makers and researchers, and can be regarded as a useful and interesting starting point for further studies.

Showing that an intervention can work (i.e. its efficacy) and quantifying its potential benefits (i.e. in this case the number of healthy life years that can be saved) is necessary, but only a first step. Where resources are limited and funding is scarce, an intervention also needs to

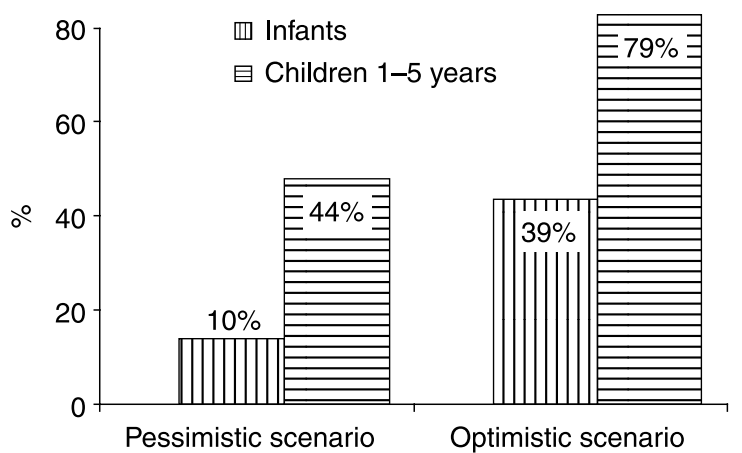

Fig. 4 The reduction of the burden of zinc deficiency through biofortification by age group be cost-effective compared with alternatives. Scarcity needs to be managed, and in public health such management is paramount. The World Development Report (WDR) ${ }^{5}$ underlines that 'because interventions can differ so much in cost-effectiveness, making allocative decisions badly in either the public or the private sectors costs lives' (p. 61). This is also why DALYs were introduced as a unit for measuring health effects: to be able to compare different interventions by what it costs to achieve an additional year of healthy life. The WDR provided a 'yardstick' for assessing the cost-effectiveness of public health initiatives by indicating that saving one DALY for less than \$US 150 is highly cost-effective. In another publication the World Bank $^{6}$ states that most micronutrient programmes cost less than \$US 50 per DALY saved, with iron fortification, iodine fortification and vitamin A supplementation to children under the age of 5 years costing \$US 4, \$US 8 and \$US 9 per DALY saved, respectively. A recent assessment of (hypothetical) zinc fortification in Southeast Asia reports a cost of international \$ 14 per DALY averted ${ }^{37}$. The World Health Organization's (WHO) Commission on Macroeconomics and Health ${ }^{38}$ classified DALY values equal to average per capita income as conservative assumptions and propagated the use of three times the per capita income to value one DALY. The Indian per capita income in 2004 was \$US $620^{39}$; hence, according to the WHO, health interventions in India can already be considered cost-effective if they save a DALY at a cost of less than \$US 1860.

Given that the above yardsticks originate from different years, the issue of inflationary adjustment becomes relevant before any comparisons can be made between the present study and these sources. To convert the nominal \$US values given in the sources cited above into real terms, the inflation calculator of the US Bureau of Labor Statistics (http://www.bls.gov/cpi) was used, which is based on the average consumer price index for a given calendar year. 2004 was selected as base year. The resulting new reference values - expressed in constant

"Here methodological differences in calculating a 'DALY' are disregarded. Yet, it is not expected that these differences would change the magnitudes of the results in a relevant manner. 
Table 5 Cost-effectiveness of zinc biofortification of wheat and rice over 30 years

\begin{tabular}{llcccc}
\hline Crop & Scenario & $\begin{array}{c}\text { Net present cost per } \\
\text { DALY saved (\$US) }\end{array}$ & $\operatorname{IRR}^{*}(\%)$ & $\begin{array}{c}\text { Net present } \\
\text { cost per life saved (\$US) }\end{array}$ & $\begin{array}{c}\text { Average annual cost per } \\
\text { citizen (\$US) }\end{array}$ \\
\hline Wheat & Pessimistic & 39.45 & 31 & 1194.03 & 0.0004 \\
& Optimistic & 1.98 & 98 & 59.70 & 0.0001 \\
Rice & Pessimistic & 3.90 & 66 & 119.37 & 0.0004 \\
\multirow{2}{*}{ Wheat and rice } & Optimistic & 0.40 & 173 & 12.03 & 0.0001 \\
& Pessimistic & 7.31 & 56 & 115.04 & 0.0009 \\
& Optimistic & 0.73 & 150 & 11.62 & 0.0003 \\
\hline
\end{tabular}

DALY - disability-adjusted life year.

* Internal rate of return (if one DALY is valued at \$US 1000)

Table 6 DALY values and thresholds for cost-effectiveness of health interventions

\begin{tabular}{|c|c|c|}
\hline & $\begin{array}{l}\text { Cost (\$US) per DALY saved } \\
\text { (respective years) }\end{array}$ & $\begin{array}{l}\text { Cost (\$US) per DALY saved } \\
\text { (constant 2004)* }\end{array}$ \\
\hline $\begin{array}{l}\text { Threshold derived from the WHO's conventional } \\
\text { valuation of one DALY }\end{array}$ & & 1860 \\
\hline $\begin{array}{l}\text { Threshold derived from the WHO's conservative } \\
\text { valuation of one DALY }\end{array}$ & & 620 \\
\hline $\begin{array}{l}\text { Threshold of the World Bank for high cost-effectiveness } \\
\text { of public health initiatives }\end{array}$ & 150 & 217 \\
\hline $\begin{array}{l}\text { Actual costs per DALY saved for different } \\
\text { micronutrient interventions }{ }^{6}\end{array}$ & $4-9$ & $5.8-13.0$ \\
\hline $\begin{array}{l}\text { Cost effectiveness of zinc fortification in } \\
\text { Southeast Asia with } 95 \% \text { coverage }^{37}\end{array}$ & $14 \dagger$ & $15.4 †$ \\
\hline $\begin{array}{l}\text { Estimated cost per DALY saved through } \\
\text { zinc biofortification }\end{array}$ & & $0.7-7.3$ \\
\hline
\end{tabular}

DALY - disability-adjusted life year; WHO - World Health Organization.

* Source: consumer price index of the US Bureau of Labor Statistics (http://www.bls.gov/cpi).

†These figures are expressed in international \$; therefore the cost-effectiveness ratios are relatively higher than those expressed in $\$$ US.

terms - are reported in Table 6. Against this background the imputed costs of \$US $0.73-7.31$ for saving one DALY through zinc biofortification of wheat and zinc (Table 5) is extremely low: compared with both other micronutrient interventions and the standards set by the World Bank and the WHO, zinc biofortification may be very cost-effective.*

In this study DALYs were used to measure the loss of health, but looking at mortality alone can provide a compelling argument for zinc biofortification of wheat and rice: deaths of infants and children can be averted for as little as \$US 12-115 per case (Table 5). Another perspective can be gained if the costs of zinc biofortification over 30 years are disaggregated to the per capita level: zinc biofortification would cost only \$US 0.0003-0.0009 per citizen in India per year (Table 5). The transition from a cost-effectiveness analysis - or a cost-utility analysis - to a cost-benefit analysis allows for the intervention to be

*If the assumed coverage rate for wheat and rice in the pessimistic scenario (of 30 and 20\%, respectively) is reduced further - to determine a switching value for this key assumption - it can be shown that with a coverage rate of only $0.25 \%$ for both crops, saving one DALY costs \$US 210, i.e. still less than the World Bank's threshold of \$US 217. With such a low coverage rate the actual objective of addressing $\mathrm{ZnD}$ comprehensively would certainly not be achieved. But the robust results on the cost-effectiveness of zinc biofortification show that the risk of a misinvestment of R\&D resources is very low. assessed not only in terms of its technical efficiency but also in terms of its allocative efficiency in a context that goes beyond the health sector ${ }^{40}$. In a similar analysis for the Philippines, Zimmermann and Qaim $^{17}$ reported internal rates of return (IRRs) of $66-133 \%$ for 'Golden Rice', " which is intended to control vitamin A deficiency. However, they used the annual per capita income of the Philippines of \$US 1030 in 2000 to value a DALY. With a somewhat lower but otherwise better comparable DALY value of $\$$ US $1000^{14}$, the IRRs for zinc biofortification in India are $56-150 \%$.

\section{Conclusion}

This study has shown that $\mathrm{ZnD}$, with an annual loss of 2.8 million healthy life years, can be considered a public health problem in India. Zinc biofortification of wheat and rice may reduce this burden by $20-51 \%$, saving the lives of 18350 or even 48100 children. At the same time zinc biofortification has the potential to be a very cost-effective intervention by any standard: saving one healthy life year is expected to cost as little as \$US 0.73-7.31 if both wheat and rice can be bred for higher zinc concentrations.

\footnotetext{
"Golden Rice' is rice that is biofortified with $\beta$-carotene, hence acquiring a yellow-golden hue.
} 
Yet, given these promising results, we concur with the World Health Report ${ }^{2}$ : 'It is not much value to provide decision-makers with information on the costs and effectiveness of interventions that are undertaken badly. Accordingly, the results reported here show what would be achieved if the interventions were undertaken in a relatively efficient manner' (p. 107). This is particularly true for the country-specific adaptive breeding efforts and adoption rates; even if HarvestPlus can provide advanced lines of zinc-rich wheat and rice, these varieties will need to reach as many farmers and consumers as soon as possible. Here we have demonstrated what the potential benefits may be to Indian society - based on reasonable assumptions. However, for these benefits to materialise, the support and the collaboration of key players in the international donor community, national agricultural research and extension agencies and national health systems are needed to generate data on their bioefficacy and acceptability, thereby proving that biofortification is cost-effective where $\mathrm{ZnD}$ is a public health problem and where wheat and rice are eaten by large parts of the population.

By controlling a large proportion of $\mathrm{ZnD}$ through biofortification, scarce resources - in terms of manpower and money - can be targeted to both direct and indirect interventions to control severe deficiency. Hence biofortification may not only save lives and prevent morbidity among millions of people, it may also help accommodate the budgetary need to economise and to allocate resources more efficiently between different interventions whether within the health sector or otherwise.

\section{Acknowledgements}

Financial support of the German Research Foundation (DFG) is gratefully acknowledged. Institutional support was provided by the Centre for Development Economics, Delhi School of Economics. We are grateful to Rekha Sharma for providing us with the unit record data on zinc intakes. Thanks are also due to Ivan Ortiz-Monasterio and Gerard Barry for data on costs, and the other scientists working on biofortification for some of the assumptions used in this paper.

\section{References}

1 United Nations Administrative Committee on Coordination, Sub-Committee on Nutrition (ACC/SCN). Fourth Report on the World Nutrition Situation. Geneva: ACC/SCN, 2000.

2 World Health Organization (WHO). The World Health Report 2002. Geneva: WHO, 2002.

3 Sanchez PA, Swaminathan MS. Enhanced: cutting world hunger in half. Science 2005; 307: 357-9.

4 Demment MW, Young MM, Sensenig RL. Providing micronutrients through food-based solutions: a key to human and national development. Journal of Nutrition 2003; 133: 3879S-85S.
5 World Bank. World Development Report 1993. Washington, DC: World Bank, 1993.

6 World Bank. Enriching Lives - Overcoming Vitamin and Mineral Malnutrition in Developing Countries. Washington, DC: World Bank, 1994

7 Horton S. Opportunities for investments in nutrition in lowincome Asia. Asian Development Review 1999; 17: 246-73.

8 Bouis HE. Plant breeding: a new tool for fighting micronutrient malnutrition. Journal of Nutrition 2002; 132: 491S-4S.

9 Welch RM, Graham RD. A new paradigm for world agriculture: productive, sustainable, nutritious, healthful food systems. Food and Nutrition Bulletin 2000; 21: 361-6.

10 Nestel P, Bouis HE, Meenakshi JV, Pfeiffer W. Biofortification of staple food crops. Journal of Nutrition 2006; 136: 1064-7.

11 Heisey PW, Lantican MA, Dubin HJ. Impacts of International Wheat Breeding Research in Developing Countries, 196697. México: Centro Internacional de Mejoramiento del Maíz y Trigo, 2002.

12 Hotz C, Brown KH, eds. Assessment of the risk of zinc deficiency in populations and options for its control. Food and Nutrition Bulletin 2004; 25(Suppl. 2): S91-204.

13 United Nations System Standing Committee on Nutrition (SCN). Fifth Report on the World Nutrition Situation. Geneva: SCN, 2004.

14 Stein AJ, Meenakshi JV, Qaim M, Nestel P, Sachdev HPS, Bhutta ZA. Analysing Health Benefits of Biofortified Staple Crops by Means of the Disability-adjusted Life Years Approach: A Handbook focusing on Iron, Zinc and Vitamin $A$. Technical Monograph No. 4. Washington, DC: HarvestPlus, 2005. Also available at http://www.harvestplus.org/ pdfs/tech04.pdf

15 National Sample Survey Organisation (NSSO). Consumer Expenditure Survey, 55th Round. Kolkata and New Delhi: NSSO, 2000.

16 Murray CJL, Lopez AD, eds. The Global Burden of Disease. Cambridge, MA: Harvard University Press, 1996.

17 Zimmermann R, Qaim M. Potential health benefits of Golden Rice: a Philippine case study. Food Policy 2004; 29: 147-68.

18 Jones G, Steketee RW, Black RE, Bhutta ZA, Morris SS. Bellagio Child Survival Study Group. How many child deaths can we prevent this year? Lancet 2003; 362: 65-71.

19 Bahl R, Baqui A, Bhan MK, Bhatnagar S, Black RE, Brooks A, et al. (2001) Effect of zinc supplementation on clinical course of acute diarrhea. Journal of Health, Population, and Nutrition $19338-46$.

20 Bhutta ZA, Bird SM, Black RE, Brown KH, Gardner JM, Hidayat A, et al. Therapeutic effect of oral zinc in acute and persistent diarrhea in children in developing countries: pooled analysis of randomized controlled trials. American Journal of Clinical Nutrition 2000; 72: 1516-22.

21 Bhutta ZA, Black RE, Brown KH, Gardner JM, Gore S, Hidayat A, et al. Prevention of diarrhea and pneumonia by zinc supplementation in children in developing countries: pooled analysis of randomized controlled trials. Zinc Investigators' Collaborative Group. Journal of Pediatrics 1999; 135: 689-97.

22 Brown KH, Peerson JM, Rivera J, Allen LH. Effect of supplemental zinc on the growth and serum zinc concentrations of prepubertal children: a meta-analysis of randomised controlled trials. American Journal of Clinical Nutrition 2002; 75: 1062-71.

23 International Institute for Population Sciences (IIPS) and ORC Macro. National Family Health Survey (NFHS-2), 1998-99: India. Mumbai: IPPS and ORC Macro, 2000.

24 United Nations Children's Fund (UNICEF). State of the World's Children. New York: UNICEF, 2004.

25 World Health Organization (WHO). Life Tables for 191 Countries - World Mortality 2000. Geneva: WHO, 2001. 
26 Census of India. Census of India 1991, Census Data Online New Delhi: Office of the Registrar General and Census Commissioner, 1991.

27 Census of India. Census of India 2001, Census Data Online. New Delhi: Office of the Registrar General and Census Commissioner, 2001.

28 Gopalan C, Rama Sastri BV, Balasubramanian S. Nutritive Value of Indian Foods. Hyderabad: National Institute of Nutrition, 1989

29 US Department of Agriculture (USDA). National Nutrient Database for Standard Reference, Release 17. Washington, DC: USDA, Nutrient Data Laboratory, 2004.

30 Behrman J. Intrahousehold allocation of nutrients in rural India: are boys favored? Do parents exhibit inequality? Oxford Economic Papers 1988; 40: 32-54.

31 Behrman JR, Deolalikar AB. The intrahousehold demand for nutrients in rural South India: individual estimates, fixed effects, and permanent income. Journal of Human Resources 1990; 25: 665-96.

32 Walker D, Fox-Rushby J. Allowing for uncertainty in economic evaluations: qualitative sensitivity analysis. Health Policy and Planning 2001; 16: 435-44.

33 International Centre for Tropical Agriculture (CIAT)/International Food Policy Research Institute (IFPRI). Biofortified Crops for Improved Human Nutrition. A Challenge
Programme Proposal. Washington, DC: CIAT and IFPRI, 2003.

34 Stein AJ, Meenakshi JV, Qaim M, Nestel P, Sachdev HPS, Bhutta ZA. Health benefits of biofortification: an ex-ante analysis of iron-rich rice and wheat in India. Paper presented at the American Agricultural Economics Association Annual Meeting, Providence, RI, USA, 24-27 July 2005.

35 The Micronutrient Initiative (MI). Controlling Vitamin \& Mineral Deficiencies in India: Meeting the Goal. New Delhi: MI, 2005.

36 Wuehler SE, Peerson JM, Brown KH. Use of national food balance data to estimate the adequacy of zinc in national food supplies: methodology and regional estimates. Public Health Nutrition 2005; 8: 812-9.

37 Tan-Torres Edejer T, Aikins M, Black R, Wolfson L, Hutubessy R, Evans DB. Cost effectiveness analysis of strategies for child health in developing countries. British Medical Journal 2005; 331: e1177.

38 World Health Organization (WHO). Macroeconomics and Health: Investing in Health for Economic Development. Report of the Commission on Macroeconomics and Health. Geneva: WHO, 2001.

39 World Bank. Country Data Profiles. World Development Indicators Database. Washington, DC: World Bank, 2005.

40 Walker D. Cost and cost-effectiveness guidelines: which ones to use? Health Policy and Planning 2001; 16: 113-21. 